\title{
Basal luteinizing hormone and follicular stimulating hormone: is it sufficient for the diagnosis of precocious puberty in girls?
}

\author{
Dong Seong Lee, MD', \\ Na Yung Ryoo, MD', \\ Sun Hee Lee, $M D^{2}$, \\ Sollip Kim, MD', \\ Jae Hyun Kim, MD ${ }^{1}$
}

${ }^{1}$ Department of Pediatrics, Inje University Ilsan Paik Hospital, Inje University College of Medicine, Goyang, ${ }^{2}$ Department of Pediatrics, Gacheon University Gil Medical Center, Graduate School of Medicine, Gacheon University of Medicine and Science, Incheon, ${ }^{3}$ Department of Laboratory Medicine, Inje University Ilsan Paik Hospital, Inje University College of Medicine, Goyang, Korea

\begin{abstract}
Purpose: A gonadotropin-releasing hormone stimulation test (GnRHST) is the gold standard in diagnosing central precocious puberty (CPP). The aim of this study was to investigate the diagnostic accuracy of basal gonadotropin levels for girls with suspected precocious puberty and to evaluate the factors affecting positive results of the GnRHST.

Methods: Korean girls with early pubertal development who visited the clinic during 2010-2012 were included. Auxological and biochemical tests were evaluated and a standard GnRHST was performed. A peak luteinizing hormone (LH) level of $\geq 5 \mathrm{IU} / \mathrm{L}$ was considered a positive response during the GnRHST.

Results: A total of 336 girls were included. The positive responses were observed in 241 girls (71.7\%), and negative responses were found in 95 girls (28.3\%). In the logistic regression analysis, the coefficient of the basal $\mathrm{LH}$ and basal $\mathrm{LH} /$ follicular stimulating hormone (FSH) ratio was $4.23(P<0.001)$ and $21.28(P<0.001)$, respectively. Receiver operating characteristic analysis showed that the basal LH/FSH ratio is a better predictor of the pubertal result after the GnRHST than the basal LH (area under the curve was 0.745 and 0.740 , respectively; $P=0.027$ ). Among 189 girls with a basal LH of $<0.1 \mathrm{IU} / \mathrm{L}, 105$ (55.6\%) had positive responses.

Conclusion: An elevated level of the basal LH and basal LH/FSH ratio was a significant predicting factor of positive responses during the GnRHST. However a GnRHST was still necessary for diagnostic confirmation of CPP because more than half of the girls with a basal LH level below the detection limit revealed to have CPP.
\end{abstract}

Keywords: Precocious puberty, Diagnosis, Luteinizing hormone, Follicular stimulating hormone

\section{Introduction}

Central precocious puberty (CPP) is caused by premature sequential activation of the hypothalamic-pituitary-ovarian (HPO) axis ${ }^{1,2}$. In girls, precocious puberty is defined as the development of secondary sexual characteristics before 8 years of age ${ }^{3)}$. Precocious puberty in girls can lead to a decreased final adult height and psychosocial problems ${ }^{4,5}$.

For demonstration of the early activation of the HPO axis in girls with pubertal development, the gold standard for laboratory confirmation of CPP is the maximal luteinizing hormone $(\mathrm{LH})$ level after gonadotropin-releasing hormone $(\mathrm{GnRH})$ stimulation $^{6.8)}$. However, the GnRH stimulation test (GnRHST) causes discomfort because of the time-consuming nature of the repeated sampling. Hence, there has been an effort to find measures that can substitute for or simplify the GnRHST. Even though the basal concentration of LH and the subcutaneous GnRH analogues stimulation test are suggested as alternatives, none of these are sufficient to substitute as a gold standard ${ }^{9-12)}$. 
The aim of this study was to investigate the diagnostic accuracy of basal gonadotropin levels for girls with suspected precocious puberty, to determine the methods for the simplification of this test, and to evaluate the factors affecting the positive results of the GnRHST.

\section{Materials and methods}

\section{Subjects}

Among the girls with early pubertal signs who visited our pediatric endocrinology clinic from 2010 to 2012, the subjects who underwent the GnRHST were selected. The inclusion criteria were breast development before the age of 8 years, sexual maturity rate of the breasts of Tanner stage 2 or more, and bone age advancement by 1 or more years. The exclusion criteria were as follows: peripheral precocious puberty, precocious puberty caused by an intracranial lesion, chronic illness, and longterm medication which could affect the HPO axis. Among 339 eligible girls, 336 were included in the study. Two had peripheral precocious puberty caused by a functional ovarian cyst and one had a hypothalamic hamartoma. This study was approved by the Institutional Review Board of Inje University Ilsan Paik Hospital.

\section{Methods}

We reviewed the medical records of the subjects retrospectively. Clinical data at the time of the GnRHST, such as the chronological age, bone age, height, body weight, body mass index (BMI), sexual maturity rate, parental height, and laboratory profiles, were collected. The standard deviation score (SDS) of the height, body weight and BMI were calculated using the 2007 Korean National Growth Charts ${ }^{13)}$. Bone age was measured using the Greulich-Pyle method ${ }^{14)}$.

The GnRHST was performed in the early morning after an overnight fast. An intravenous cannula was placed in the forearm before the test. Basal serum samples for LH, follicular stimulating hormone (FSH) and estradiol were drawn immediately before the administration of $100 \mu \mathrm{g}$ of GnRH (Relefact; Sanofi-Aventis, Frankfurt, Germany). After injection, blood samples for LH and FSH were collected at 30, 45, 60 and 90 minutes.

Serum LH, FSH and estradiol were measured using an electrochemiluminescence immunoassay (ECLIA) (Roche Diagnostics GmbH, Manheim, Germany). The range of withinrun precision and total precision of the hormonal assays was as follows: $0.7-1.2 \%$ and $1.6-2.2 \%$ for $\mathrm{LH} ; 2.5-2.8 \%$ and $3.6-4.5 \%$, for FSH; $1.7-3.3 \%$ and $2.2-4.7 \%$ for estradiol, respectively. The limit of detection of LH, FSH and estradiol was $0.1 \mathrm{IU} / \mathrm{L}, 0.1 \mathrm{IU} /$ $\mathrm{L}$ and $5.0 \mathrm{pg} / \mathrm{mL}$, respectively. A peak LH concentration of $\geq 5$ IU/L on the GnRHST was regarded as a positive response ${ }^{15)}$.

\section{Statistics}

Statistical analyses were performed using Stata 12.1 (StataCorp LP., College Station, TX, USA). Results were described as the mean \pm standard deviation. Student $t$-test was used to compare values between the two groups. Pearson correlation was used to evaluate the relationships between basal LH, FSH and peak

Table 1. Clinical and biochemical characteristics of the subjects

\begin{tabular}{|c|c|c|c|c|}
\hline Characteristic & Total & Negative response to GnRHST & Positive response to GnRHST & $P$-value \\
\hline Subjects, n (\%) & $336(100)$ & $95(28.3)$ & $241(71.7)$ & \\
\hline Chronological age (yr) & $8.27 \pm 0.57$ & $8.24 \pm 0.57$ & $8.28 \pm 0.57$ & 0.491 \\
\hline Bone age (yr) & $9.88 \pm 0.75$ & $9.89 \pm 0.70$ & $9.87 \pm 0.77$ & 0.854 \\
\hline Bone age-chronological age (yr) & $1.61 \pm 0.63$ & $1.65 \pm 0.54$ & $1.59 \pm 0.67$ & 0.413 \\
\hline Height SDS & $0.81 \pm 0.85$ & $0.92 \pm 0.77$ & $0.76 \pm 0.87$ & 0.110 \\
\hline Body mass index SDS & $0.37 \pm 1.01$ & $0.58 \pm 1.16$ & $0.29 \pm 0.93$ & 0.018 \\
\hline Basal LH (IU/L) & $0.40 \pm 0.87$ & $0.04 \pm 0.13$ & $0.54 \pm 0.99$ & $<0.001$ \\
\hline Peak LH (IU/L) & $12.11 \pm 12.33$ & $3.45 \pm 1.02$ & $15.52 \pm 13.06$ & $<0.001$ \\
\hline Basal FSH (IU/L) & $2.80 \pm 1.64$ & $2.02 \pm 1.25$ & $3.10 \pm 1.68$ & $<0.001$ \\
\hline Peak FSH (IU/L) & $13.83 \pm 4.97$ & $12.17 \pm 4.10$ & $14.49 \pm 5.14$ & $<0.001$ \\
\hline Basal LH/FSH ratio & $0.10 \pm 0.21$ & $0.01 \pm 0.03$ & $0.14 \pm 0.24$ & $<0.001$ \\
\hline Peak LH/FSH ratio & $0.91 \pm 0.88$ & $0.30 \pm 0.11$ & $1.16 \pm 0.93$ & $<0.001$ \\
\hline Estradiol (pg/mL) & $15.37 \pm 15.33$ & $12.87 \pm 12.00$ & $16.35 \pm 16.38$ & 0.061 \\
\hline |GF-| & $300 \pm 99$ & $268 \pm 88$ & $311 \pm 102$ & $<0.001$ \\
\hline IGF-ISDS & $0.73 \pm 1.13$ & $0.41 \pm 0.97$ & $0.85 \pm 1.17$ & 0.001 \\
\hline IGFBP-3 & $4819 \pm 821$ & $4746 \pm 971$ & $4825 \pm 788$ & 0.528 \\
\hline IGFBP-3 SDS & $3.64 \pm 1.56$ & $3.58 \pm 1.75$ & $3.65 \pm 1.49$ & 0.725 \\
\hline Alkaline phosphatase (IU/L) & $305 \pm 70$ & $299 \pm 79$ & $308 \pm 66$ & 0.298 \\
\hline Target height SDS & $-0.23 \pm 0.69$ & $-0.10 \pm 0.68$ & $-0.28 \pm 0.68$ & 0.033 \\
\hline
\end{tabular}

Values are presented as mean \pm standard deviation unless otherwise indicated.

GnRHST, gonadotrpopin-releasing hormone stimulation test; SDS, standard deviation score; LH, luteinizing hormone; FSH, follicular stimulating hormone; IGF-I, insulin-like growth factor-l; IGFBP-3, insulin-like growth factor binding protein-3. 
LH concentration after the GnRHST. Logistic regression analysis was performed to determine the association between a positive response to the GnRHST and other variables. Receiver operating curve (ROC) analyses were carried out to investigate the predictive capacity of the variables ${ }^{16)}$. The Youden index (J), which is defined by "J=maximum (sensitivity+specificity-1)", was used to determine the optimal cutoff value ${ }^{17)}$. A $P$-value $<0.05$ was considered statistically significant.

\section{Results}

\section{Characteristics of the study subjects}

Among 336 subjects, 241 (71.7\%) showed a positive response and $95(28.3 \%)$ showed a negative response after the GnRHST (Table 1 ). The mean chronological age was $8.28 \pm 0.57$ years in the positive group and $8.24 \pm 0.57$ years in the negative group $(P=0.491)$. The mean bone age was $9.87 \pm 0.77$ years in the positive group and $9.89 \pm 0.70$ years in the negative group $(P=0.854)$. The difference between the chronological age and bone age was $1.59 \pm 0.67$ years in the positive group and $1.65 \pm 0.54$ years in the negative group $(P=0.413)$. The BMI SDS and target height SDS were significantly higher in the negative group, although the height SDS showed no significant difference between the two groups.

\section{Analysis of $\mathrm{GnRH}$ stimulation tests}

Basal LH, basal FSH, basal LH/FSH ratio, peak LH, peak FSH and peak LH/FSH ratio were significantly higher in the positive group (Table 1). However insulin-like growth factor-I (IGF-I) and IGF SDS were significantly higher in the positive group. Estradiol, IGF binding protein-3 and alkaline phosphatase (ALP) were not significantly different.

In the positive group, the time to reach peak LH concentration after $\mathrm{GnRH}$ administration was 30 minites in 140 patients (58.1\%) and 45 minutes in 98 patients (40.7\%). A LH level of $\geq 5$ IU/L was achieved in 233 patients $(96.7 \%)$ at 30 minutes and $240(99.6 \%)$ in 45 minutes. All patients in the pubertal group showed an LH concentration of $\geq 5 \mathrm{IU} / \mathrm{L}$ by 45 minutes after GnRH administration.

Table 2. Multiple logistic regression analysis of factors affecting the positive results of the gonadotropin-releasing hormone stimulation test

\begin{tabular}{llccr}
\hline Model & \multicolumn{1}{c}{ Variable } & Coefficient & Standard error & $P$-value \\
\hline 1 & Basal LH & 4.23 & 1.20 & $<0.001$ \\
& Basal FSH & 0.17 & 0.13 & 0.198 \\
& Body mass index SDS & -0.24 & 0.19 & 0.059 \\
& Target height SDS & -0.29 & 0.20 & 0.153 \\
2 & Basal LH/FSH ratio & 21.28 & 4.41 & $<0.001$ \\
& Body mass index SDS & -0.24 & 0.13 & 0.062 \\
& Target height SDS & -0.32 & 0.20 & 0.116 \\
\hline
\end{tabular}

LH, luteinizing hormone; FSH, follicular stimulating hormone; SDS, standard deviation score.

\section{Logistic regression analysis}

Univariate logistic regression analysis was performed to evaluate the factors affecting the results of the GnRH stimulation test. Basal LH, basal FSH, basal LH to FSH ratio, BMI SDS and target height (TH, [maternal height + paternal height]/2-6.5) SDS were significantly correlated. Multiple logistic regression analysis was performed using these variables. To avoid muticollinearity, 2 models were constructed (Table 2). Model 1 included basal LH, basal FSH, BMI SDS and TH SDS; otherwise model 2 included the basal LH to FSH ratio, BMI SDS and TH SDS. A significant predictor of the positive result of the GnRHST was the basal LH in model 1 and the basal LH to FSH ratio in model 2.

\section{ROC analysis}

ROC curves were constructed for the all subjects. The area under the curve (AUC) of LH was 0.740 (95\% confidence interval [CI], 0.698 to 0.781 ) and that of the basal LH to FSH ratio was 0.745 (95\% CI, 0.705 to 0.786 ) (Fig. 1). The AUC of the basal $\mathrm{LH}$ to FSH ratio was significantly bigger than that of $\mathrm{LH}$ $(P=0.027)$.

Based on the ROC curve, the optimal cutoff value of the basal $\mathrm{LH}$ associated with a positive response was $0.1 \mathrm{IU} / \mathrm{L}$, which demonstrated a sensitivity of $56.4 \%$ and a specificity of $88.4 \%$. The best cutoff point of the basal LH to FSH ratio was 0.04 , where the sensitivity was $54.4 \%$ and the specificity was $93.7 \%$.

\section{Analysis of subjects with a basal $\mathrm{LH}<0.1 \mathrm{IU} / \mathrm{L}$}

Among 189 subjects with a basal LH below the detection limit, positive results were reported in 105 patients (55.6\%). In

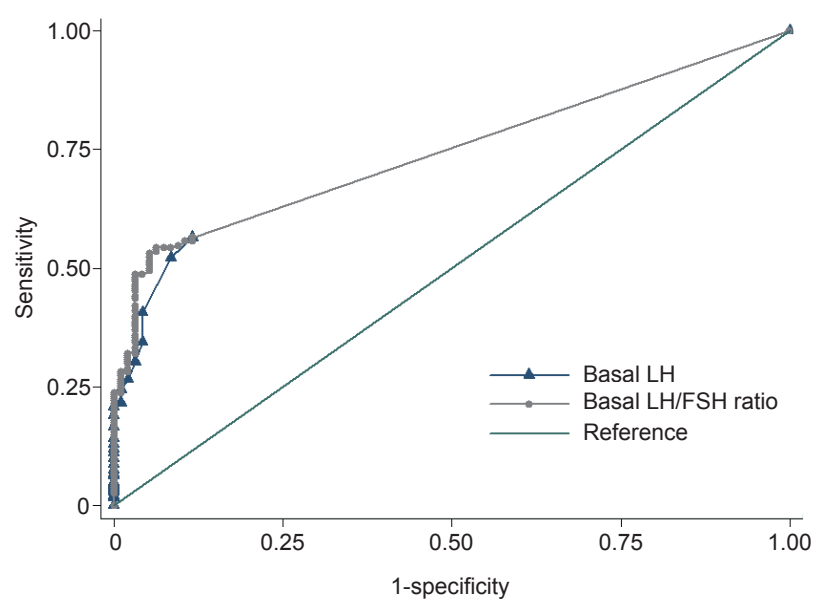

Fig. 1. Receiver operator characteristic curves of various thresholds of basal LH levels (area under the curve [AUC], 0.740; $95 \%$ confidence interval [CI], 0.698 to 0.781 ) and basal LH/FSH ratio (AUC, $0.745 ; 95 \% \mathrm{Cl}, 0.705$ to 0.786 ), for predicting central precocious puberty. LH, luteinizing hormone; FSH, follicular stimulating hormone. 
this subgroup analysis, basal FSH, peak LH, peak FSH and peak $\mathrm{LH} / \mathrm{FSH}$ ratio were significantly higher in the positive response group (data not shown). In the logistic regression analysis, the basal FSH was significantly correlated with positive results $(P=0.0011)$. The AUC of the basal FSH was 0.64 (95\% CI, 0.56 to 0.72 ) in the ROC analysis. The best cutoff point of the basal FSH was $1.3 \mathrm{U} / \mathrm{L}$ for the positive response, for which the sensitivity was 0.89 and specificity was 0.36 . The probability of a positive response after GnRHST increased with the increasing basal FSH in both $\mathrm{LH}<0.1 \mathrm{IU} / \mathrm{L}$ and $\mathrm{LH} \geq 0.1 \mathrm{IU} / \mathrm{L}$ group. (Fig. 2)

\section{Discussion}

The GnRHST is the gold standard for the diagnosis of precocious puberty. However, the GnRHST is time-consuming, expensive and inconvenient for patients and labor-intensive for clinicians. Moreover, the GnRHST showed a negative response in $22.9 \%$ to $37.1 \%$ of subjects suspected to have precocious puberty ${ }^{18-20)}$. To reduce the rate of negative responses, it is critical to select subjects who have a high possibility of showing positive results on the GnRHST.

In this study, LH and FSH were measured using the ECLIA method which developed recently. ECLIA is a recently developed method with high sensitivity, specificity, rapidity and reproducibility, which has replaced the former radioimmunoassay ${ }^{21)}$. Among 147 female subjects with a basal LH $\geq 0.1 \mathrm{IU} / \mathrm{L}, 136$ girls (92.5\%) showed a positive response on the GnRHST, indicating the sensitivity was $56.4 \%$ and specificity was $88.4 \%$ In the case of a basal LH/FSH ratio $\geq 0.04,131$ out of 137 girls (95.6\%) showed a positive response, which indicated a sensitivity and specificity of $54.4 \%$ and $93.7 \%$, respectively. In this study, the specificity was $100 \%$ when the basal LH was $\geq 0.9$ IU/L or basal LH/FSH was 0.19 . According to the ROC analysis, the basal LH/FSH ratio was the better method for predicting a positive result after the GnRHST.

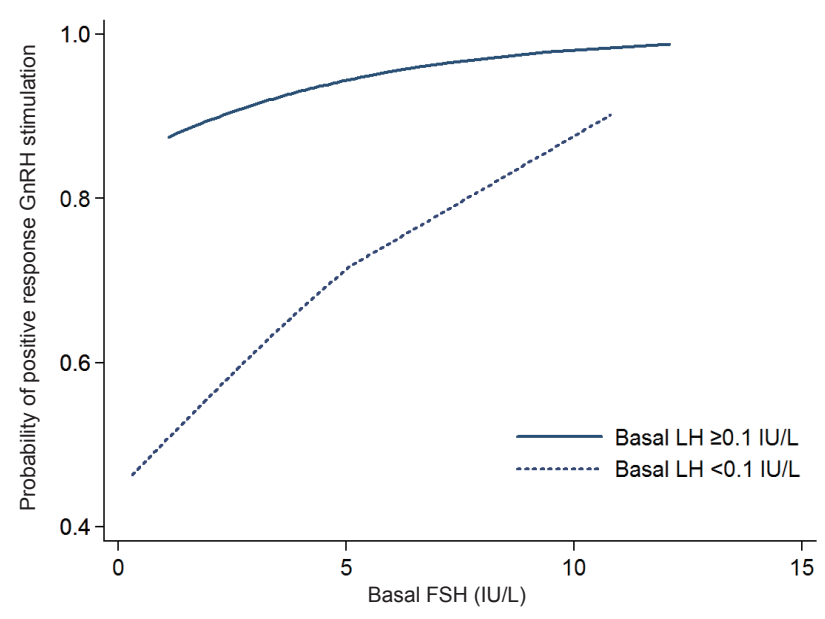

Fig. 2. Probability of positive response after gonadotropin-releasing hormone (GnRH) stimulation according to basal luteinizing hormone (LH) and basal follicular stimulating hormone (FSH).
A spontaneous LH value of $>0.1$ IU/L with immunochemiluminometric assay had diagnostic value for the detection of CPP with a sensitivity of $94 \%$ of and a specificity of $88 \%$ in a study ${ }^{9}$. A cutoff value of $\mathrm{LH}>0.3 \mathrm{IU} / \mathrm{L}$ increased the specificity to $100 \%$, although the sensi-tivity decreased. Lee et al. ${ }^{19)}$ reported that basal $\mathrm{LH}$ with $\geq 1.1 \mathrm{IU} / \mathrm{L}$ with immunoradiometric assay is related pubertal response to GnRHST, which showed $69.1 \%$ of sensitivity and $50.5 \%$ of specificity. Pasternak et al. ${ }^{22)}$ suggested that a basal LH $>0.1 \mathrm{IU} / \mathrm{L}$ using chemiluminescent immunometric assay was sufficient for the diagnosis of CPP, which showed $94.7 \%$ of sensitivity and $64.4 \%$ of specificity. They showed that basal LH/FSH ratio of 0.05 was cutoff value with $71.4 \%$ sensitivity and $86.8 \%$ specificity, which was inferior to basal LH. In this study, when the basal $\mathrm{LH}$ was $\geq 0.1 \mathrm{IU} / \mathrm{L}$ or the basal LH/FSH ratio was $\geq 0.04$, as measured using ECLIA, the diagnosis of CPP was more likely. The cutoff with basal LH $\geq 0.1 \mathrm{IU} / \mathrm{L}$ showed $92.5 \%$ of positive predictive value (PPV) and $44.4 \%$ of negative predictive value (NPV). In case of basal LH/ FSH $\geq 0.04$, PPV and NPV was $95.6 \%$ and $44.7 \%$, respectively. Therefore, additional studies are needed for the confirmation of CPP because of the relatively low sensitivity and NPV.

In this study 185 of 241 subjects (43.6\%) with a positive response to the GnRHST showed a basal LH that was below the detection limit. Moreover a substantial number of subjects with suspicious to have precocious puberty (189 among 336 subjects, $56.3 \%$ ) was undetectable basal LH concentration, although basal $\mathrm{LH}$ with $>0.1 \mathrm{IU} / \mathrm{L}$ showed high sensitivity and specificity for the diagnosis of CPP. Therefore it is indispensable to find parameters to discriminate girls with positive response in the group with basal $\mathrm{LH}<0.1 \mathrm{IU} / \mathrm{L}$. In this study logistic regression analysis showed that the basal FSH was correlated with a positive response to GnRHST. The probability of a positive response after GnRHST showed tendency to increase with basal FSH even in basal LH with below detection limit. However the probability of a positive response was still low when basal FSH was sufficiently high. The sensitivity and specificity of basal FSH were relatively low and the AUC in the ROC analysis was 0.64 , which was not high ${ }^{7,923)}$. Therefore, the basal FSH alone seemed not be suitable for the initial screening test for diagnosing CPP. Moreover, bone age, bone age advancement and BMI were not associated with a positive response after the GnRHST.

The peak LH concentration in the positive response group was highest at 30 minutes after GnRH administration. In a positive response group, $99.6 \%$ of the patients showed a peak LH level of $\geq 5$ IU/L 45 minutes after GnRH stimulation. In all subjects with a positive response, the two samples, 30 and 45 minutes after GnRH injection, demonstrated a 100\% peak LH level of $\geq 5$ IU/L. Previous studies have suggested that LH levels between 30 and 60 minutes after GnRH stimulation are sufficient for the diagnosis of $\mathrm{CPP}^{18,24-26)}$. Two samples, obtained 30 and 45 minutes after GnRH stimulation, were able to accurately diagnose all CPP patients in this study.

In conclusion, a basal $\mathrm{LH} \geq 0.1 \mathrm{IU} / \mathrm{L}$ or a basal $\mathrm{LH} / \mathrm{FSH}$ ratio $\geq 0.04$ could be a significant predictor of a positive response during the GnRHST. However CPP was demonstrated among 
the substantial number of subjects, who showed a basal LH below detection limit or basal LH/FSH ratio $<0.01$, even using highly sensitive ECLIA. Therefore GnRHST is still essential for the diagnostic confirmation of CPP. A simplification of GnRHST, with samples drawn at 30 and 45 minutes, is sufficient for the diagnosis of CPP.

\section{Conflict of interest}

No potential conflict of interest relevant to this article was reported.

\section{Acknowledgments}

This work was supported by grant from Inje University, 2011.

\section{References}

1. Parent AS, Teilmann G, Juul A, Skakkebaek NE, Toppari J, Bourguignon JP. The timing of normal puberty and the age limits of sexual precocity: variations around the world, secular trends, and changes after migration. Endocr Rev 2003;24:668-93.

2. Lee PA. Central precocious puberty: an overview of diagnosis, treatment, and outcome. Endocrinol Metab Clin North Am 1999;28:901-18.

3. Carel JC, Leger J. Clinical practice: precocious puberty. N Engl J Med 2008;358:2366-77.

4. Brauner R, Adan L, Malandry F, Zantleifer D. Adult height in girls with idiopathic true precocious puberty. J Clin Endocrinol Metab 1994;79:415-20.

5. Mrug S, Elliott M, Gilliland MJ, Grunbaum JA, Tortolero SR, Cuccaro P, et al. Positive parenting and early puberty in girls: protective effects against aggressive behavior. Arch Pediatr Adolesc Med 2008; 162:781-6.

6. Lee PA. Laboratory monitoring of children with precocious puberty. Arch Pediatr Adolesc Med 1994;148:369-76.

7. Resende EA, Lara BH, Reis JD, Ferreira BP, Pereira GA, Borges MF. Assessment of basal and gonadotropinreleasing hormone-stimulated gonadotropins by immunochemiluminometric and immunofluorometric assays in normal children. J Clin Endocrinol Metab 2007;92:1424-9.

8. Brito VN, Batista MC, Borges MF, Latronico AC, Kohek $\mathrm{MB}$, Thirone AC, et al. Diagnostic value of fluorometric assays in the evaluation of precocious puberty. J Clin Endocrinol Metab 1999;84:3539-44.

9. Neely EK, Wilson DM, Lee PA, Stene M, Hintz RL. Spontaneous serum gonadotropin concentrations in the evaluation of precocious puberty. J Pediatr 1995;127:47-52.

10. Houk CP, Kunselman AR, Lee PA. Adequacy of a single unstimulated luteinizing hormone level to diagnose central precocious puberty in girls. Pediatrics 2009;123:e1059-63.

11. Ibáñez L, Potau N, Zampolli M, Virdis R, Gussinye M,
Carrascosa A, et al. Use of leuprolide acetate response patterns in the early diagnosis of pubertal disorders: comparison with the gonadotropin-releasing hormone test. J Clin Endocrinol Metab 1994;78:30-5.

12. Freire AV, Escobar ME, Gryngarten MG, Arcari AJ, Ballerini MG, Bergada I, et al. High diagnostic accuracy of subcutaneous Triptorelin test compared with GnRH test for diagnosing central precocious puberty in girls. Clin Endocrinol (Oxf) 2013;78:398-404.

13. Moon JS, Lee SY, Nam CM, Choi JM, Choe BK, Seo JW, et al. 2007 Korean National Growth Charts: review of developmental process and an outlook. Korean J Pediatr 2008;51:1-25.

14. Greulich WW, Pyle SI. Radiologic atlas of skeletal development of the hand and wrist. 2nd ed. Standford (CA): Stanford University Press, 1959.

15. Carel JC, Eugster EA, Rogol A, Ghizzoni L, Palmert MR; ESPE-LWPES GnRH Analogs Consensus Conference Group, et al. Consensus statement on the use of gonadotropin-releasing hormone analogs in children. Pediatrics 2009;123:e752-62.

16. Akobeng AK. Understanding diagnostic tests 3: receiver operating characteristic curves. Acta Paediatr 2007;96:6447 .

17. Youden WJ. Index for rating diagnostic tests. Cancer 1950;3:32-5.

18. Kim HK, Kee SJ, Seo JY, Yang EM, Chae HJ, Kim CJ. Gonadotropin-releasing hormone stimulation test for precocious puberty. Korean J Lab Med 2011;31:244-9.

19. Lee HS, Park HK, Ko JH, Kim YJ, Hwang JS. Utility of Basal luteinizing hormone levels for detecting central precocious puberty in girls. Horm Metab Res 2012;44:851-4.

20. Nam HK, Rhie YJ, Son CS, Park SH, Lee KH. Factors to predict positive results of gonadotropin releasing hormone stimulation test in girls with suspected precocious puberty. J Korean Med Sci 2012;27:194-9.

21. Bidlingmaier M, Freda PU. Measurement of human growth hormone by immunoassays: current status, unsolved problems and clinical consequences. Growth Horm IGF Res 2010;20:19-25.

22. Pasternak Y, Friger M, Loewenthal N, Haim A, Hershkovitz E. The utility of basal serum LH in prediction of central precocious puberty in girls. Eur J Endocrinol 2012;166:2959.

23. Cavallo A, Richards GE, Busey S, Michaels SE. A simplified gonadotrophin-releasing hormone test for precocious puberty. Clin Endocrinol (Oxf) 1995;42:641-6.

24. Cavallo A, Zhou XH. LHRH test in the assessment of puberty in normal children. Horm Res 1994;41:10-5.

25. Eckert KL, Wilson DM, Bachrach LK, Anhalt H, Habiby RL, Olney RC, et al. A single-sample, subcutaneous gonadotropin-releasing hormone test for central precocious puberty. Pediatrics 1996;97:517-9.

26. Brito VN, Latronico AC, Arnhold IJ, Mendonca BB. A single luteinizing hormone determination 2 hours after 
apen Lee $\mathrm{DS}$, et al. • Basal gonadotropin levels for diagnosing precocious puberty

depot leuprolide is useful for therapy monitoring of

Endocrinol Metab 2004;89:4338-42. gonadotropin-dependent precocious puberty in girls. J Clin 